\title{
Sulfatase 2 Modulates Fate Change from Motor Neurons to Oligodendrocyte Precursor Cells through Coordinated Regulation of Shh Signaling with Sulfatase 1
}

\author{
Wen Jiang $^{a, b}$ Yugo Ishino $^{b}$ Hirokazu Hashimoto ${ }^{a, b}$ Kazuko Keino-Masu ${ }^{c}$ \\ Masayuki Masu $^{c} K_{\text {Kenji Uchimurad Kenji Kadomatsu }}{ }^{d}$ Takeshi Yoshimura $^{a}$ b \\ Kazuhiro Ikenaka ${ }^{a, b}$ \\ aDepartment of Physiological Sciences, School of Life Sciences, The Graduate University for Advanced Studies, \\ Okazaki, and ${ }^{b}$ Division of Neurobiology and Bioinformatics, National Institute for Physiological Sciences, National \\ Institute of Natural Sciences, Okazaki, ' Department of Molecular Neurobiology, Faculty of Medicine, University of \\ Tsukuba, Tsukuba, and d Department of Biochemistry, Nagoya University Graduate School of Medicine, Nagoya, \\ Japan
}

\section{Keywords}

Sulfatase $2 \cdot$ Sonic hedgehog $\cdot$ Spinal cord .

Oligodendrocytes $\cdot$ Motor neurons

\begin{abstract}
Sulfatases (Sulfs) are a group of endosulfatases consisting of Sulf1 and Sulf2, which specifically remove sulfate from heparan sulfate proteoglycans. Although several studies have shown that Sulf1 acts as a regulator of sonic hedgehog (Shh) signaling during embryonic ventral spinal cord development, the detailed expression pattern and function of Sulf2 in the spinal cord remains to be determined. In this study, we found that Sulf2 also modulates the cell fate change from motor neurons (MNs) to oligodendrocyte precursor cells (OPCs) by regulating Shh signaling in the mouse ventral spinal cord in coordination with Sulf1. In the mouse, Sulf mRNAs colocalize with Shh mRNA and gradually expand dorsally from embryonic day (E) 10.5 to E12.5, following strong
\end{abstract}

๑ 2017 S. Karger AG, Basel

\section{KARGER}

E-Mail karger@karger.com

www.karger.com/dne
Patched 1 signals (a target gene of Shh signaling). This coordinated expression pattern led us to hypothesize that in the mouse, strong Shh signaling is induced when Shh is released by Sulf1/2, and this strong Shh signaling subsequently induces the dorsal expansion of Shh and Sulf1/2 expression. Consistent with this hypothesis, in the ventral spinal cord of Sulf1 knockout (KO) or Sulf2 KO mice, the expression patterns of Shh and Patched 1 differed from that in wild-type mice. Moreover, the position of the pMN and p3 domains were shifted ventrally, MN generation was prolonged, and OPC generation was delayed at E12.5 in both Sulf1 KO and Sulf2 $\mathrm{KO}$ mice. These results demonstrated that in addition to Sulf1, Sulf2 also plays an important and overlapping role in the MN-to-OPC fate change by regulating Shh signaling in the ventral spinal cord. However, neither Sulf1 nor Sulf2 could compensate for the loss of the other in the developing

W.J. and Y.I. contributed equally to this work. 
mouse spinal cord. In vitro studies showed no evidence of an interaction between Sulf1 and Sulf2 that could increase sulfatase activity. Furthermore, Sulf1/2 double heterozygote and Sulf $1 / 2$ double KO mice exhibited phenotypes similar to the Sulf1 KO and Sulf2 KO mice. These results indicate that there is a threshold for sulfatase activity (which is likely reflected in the dose of Shh) required to induce the MN-to-OPC fate change, and Shh signaling requires the coordinated activity of Sulf 1 and Sulf 2 in order to reach that threshold in the mouse ventral spinal cord.

๑) 2017 S. Karger AG, Basel

\section{Introduction}

In the developing ventral spinal cord, sonic hedgehog (Shh) acts as a morphogen providing positional information to regulate cell fate decisions and structural organization in the ventral midline. Shh is secreted from the notochord and floor plate, and spreads to form a gradient along the dorsoventral axis [1-3]. Depending on the concentration and duration of Shh exposure, Shh signaling regulates the activity of Gli transcriptional factors in the responding cells to control the expression of numerous target genes, such as Patched 1 and other transcription factors in the ventral progenitor cells, to establish 5 distinct domains: p0, p1, p2, pMN, and p3 (listed from dorsal to ventral) [4-7]. After completion of domain formation, each progenitor domain generates distinct neuronal subtypes: V0, V1, V2, motor neurons (MN), and V3 neurons, respectively [8]. The 2 most ventral neural progenitor domains, $\mathrm{p} 3$ and $\mathrm{pMN}$, are defined by the expression of the transcription factors $\mathrm{Nkx} 2.2$ and Olig2, respectively [8]. In the mouse, $\mathrm{pMN}$ progenitors produce MNs during early embryonic stages (embryonic days E9-10.5) when neurogenin 2 (Ngn2) expression overlaps with Olig2 [9]. After completion of MN production, Olig2 progenitors undergo a change in cell fate to become oligodendrocyte precursor cells (OPCs) by E12.5 in the mouse. At this stage, the $\mathrm{Nkx} 2.2$-expressing region expands into the pMN domain following the downregulation of Ngn2 expression in response to increased Shh signaling, and Olig2+Nkx2.2+ cells differentiate into OPCs $[10,11]$. Especially a temporal activation of Shh signaling in Olig2+ cells at this developmental stage is a key factor for the cell fate change [12]. Thus, precise regulation of Shh signaling is required not only for domain formation but also for the MN-to-OPC neuroglial switch in the developing spinal cord [13-16]. However, the mechanism that regulates the spatiotemporal gradient of Shh remains unclear.
Many studies have demonstrated that heparan sulfate (HS) proteoglycans (HSPGs) play critical roles in regulating morphogen gradients and signaling activity [17-23]. HSPGs are extracellular matrix macromolecules that consist of a core protein (e.g., glypican, syndecan, and perlecan) and HS glycosaminoglycan chains, which attach to the core protein [24]. HS consists of uronic acid$(\beta 1 \rightarrow 4)$-D-glucosamine-repeating disaccharide subunits and undergoes sulfate modifications at the $2-O$ position on uronic acid and the $\mathrm{N}, 3-\mathrm{O}$ and $6-\mathrm{O}$ positions on the glucosamine HS units [24]. These modifications are important for the regulation of numerous morphogen gradients and signaling pathways, including Shh signaling [25]. For the 6-O-sulfate modification, 2 secretory proteins, Sulf1 and Sulf2, are important enzymes which specifically remove 6-O-sulfate groups from HS [26]. In Drosophila and Xenopus, Sulf1 influences the Shh gradient by releasing Shh from the cell surface [27, 28]. Moreover, recent studies have shown that during development Sulf1 acts as a regulator of Shh signaling input into the pMN domain to regulate OPC differentiation in chick, zebrafish, and mouse $[12,29,30]$. Another sulfatase, Sulf2, which has similar enzymatic activity and specificity as Sulf1, is also expressed in the developing ventral spinal cord [31,32], but its function in this context is completely unknown.

In this study, we analyzed various Sulf KO mice, including Sulf1 KO, Sulf2 KO, Sulf double KO (DKO) and Sulf1/2 double heterozygous (Sulf DHe) mice, and we found that in the ventral spinal cord, both Sulf1 and Sulf2 activity is necessary for the precise $\mathrm{MN}$-to-OPC fate switch.

\section{Materials and Methods}

Animals

Sulf1 and Sulf2 mutant C57BL/6 mice [33] were used for all experiments. Mice were mated to obtain pregnant mice for the collection of embryos. Noon on the plugged date was considered to be E0.5. All experiments were carried out with the permission of the Animal Care and Use Committee of the University of Tsukuba.

\section{Reagents and Antibodies}

The primary antibodies used in this study were as follows: mouse anti-Nkx2.2 IgG (DSHB), mouse anti-Islet1/2 IgG (DSHB), rabbit anti-Olig2 IgG (Millipore), rabbit anti-Sulf1 IgG (Abcam), mouse anti-Sulf2 IgG (Abcam), and mouse anti-His-tag (MBL, Nagoya, Japan).

For immunohistochemistry, the following secondary antibodies were used: Alexa 488-conjugated anti-rabbit IgG, Alexa 568-conjugated anti-rabbit IgG, Alexa 488-conjugated anti-mouse IgG, Alexa 568-conjugated anti-mouse IgG (Life Technologies),
Dev Neurosci 2017;39:361-374

DOI: $10.1159 / 000464284$
362
Jiang et al. 
and biotinylated anti-rabbit IgG (Vector Laboratories). For Western blotting, we used anti-mouse IgG-HRP (MP Biomedicals) as the second antibody.

Tissue Preparation

Embryos were decapitated, and the bodies were fixed with $4 \%$ paraformaldehyde in PBS overnight at $4{ }^{\circ} \mathrm{C}$. The bodies were then cryoprotected with $20 \%$ sucrose/PBS, embedded in Tissue-Tek OCT (optimal cutting temperature) compound (Sakura Finetechnical Co. Ltd., Tokyo, Japan) and quickly frozen in liquid nitrogen. Spinal cords were sectioned at a thickness of $20 \mu \mathrm{m}$ at the level of the forelimbs using a cryostat (CM-3050; Leica) and then thaw mounted onto RNase-free MAS (Matsunami-adhesive-silane)coated glass slides (Matsunami Glass, Osaka, Japan). These sections were used for in situ hybridization, immunohistochemistry, and immunofluorescence.

\section{In situ Hybridization}

Digoxigenin (DIG)-labeled single-strand riboprobes were synthesized using T7, T3, or SP6 RNA polymerase and DIG RNA labeling mix (Roche). In situ hybridization was performed as described previously [34]. Briefly, the sections were treated with proteinase $\mathrm{K}(1 \mu \mathrm{g} / \mathrm{ml}$ for $30 \mathrm{~min}$ at room temperature $)$ and hybridized overnight at $60^{\circ} \mathrm{C}$ with DIG-labeled antisense riboprobes in a hybridization solution consisting of $40 \%$ formamide, $20 \mathrm{~mm}$ Tris$\mathrm{HCl}(\mathrm{pH} 7.5), 600 \mathrm{~mm} \mathrm{NaCl}, 1 \mathrm{~mm}$ EDTA, 10\% dextran sulfate, $200 \mu \mathrm{g} / \mathrm{ml}$ yeast tRNA, $1 \times$ Denhardt's solution, and $0.25 \%$ SDS. The sections were washed three times in $1 \times \mathrm{SSC}(150 \mathrm{mM} \mathrm{NaCl}$ and $15 \mathrm{~mm}$ trisodium citrate) containing $50 \%$ formamide at $60^{\circ} \mathrm{C}$, followed by $0.1 \mathrm{M}$ maleic buffer ( $\mathrm{pH} 7.5$ ) containing $0.1 \%$ Tween 20 and $0.15 \mathrm{M} \mathrm{NaCl}$. The bound DIG-labeled probe was detected by overnight incubation of the sections with anti-DIG antibody conjugated to alkaline phosphatase (Roche), and the color was developed in the presence of 4-nitro blue tetrazolium chloride and 5-bromo-4-chloro-3-indolylphosphate in the dark at room temperature. After alkaline phosphatase-mediated visualization, some sections were incubated with an anti-Nkx2.2 antibody or antiOlig2 antibody, followed by biotin-conjugated secondary antibodies, and then visualized using an ABC Elite kit (Vector Laboratories) and diaminobenzidine (DAB) as a chromogen. The sections were washed in cold PBS to quench the reaction and then mounted with Permount (Thermo Fisher Scientific) after serial dehydration.

\section{Immunofluorescence and Immunohistochemistry}

Transverse cryosections $(20 \mu \mathrm{m})$ of the embryonic spinal cord were heated in a microwave oven $(550 \mathrm{~W})$ for $5 \mathrm{~min}$ in $10 \mathrm{mM} \mathrm{ci}$ trate buffer ( $\mathrm{pH}$ 6.0) for antigen retrieval, then cooled to room temperature. After antigen retrieval, the sections were blocked with $10 \%$ normal goat serum/PBS containing $0.1 \%$ Triton X-100 for $1 \mathrm{~h}$, then incubated at $4{ }^{\circ} \mathrm{C}$ overnight with primary antibodies diluted in blocking buffer. After washing with PBS-T $0.1 \%$ Triton $\mathrm{X}-100 / \mathrm{PBS}$ ), sections were incubated for $2 \mathrm{~h}$ at room temperature with Alexa 488- and/or Alexa 568-conjugated secondary antibodies diluted in blocking buffer. After incubation with secondary antibodies, the sections were washed in PBS, and cell nuclei were counterstained with Hoechst $33342(0.1 \mu \mathrm{g} / \mathrm{ml}$; Sigma). For visualization with $\mathrm{DAB}$, the sections were treated with $3 \% \mathrm{H}_{2} \mathrm{O}_{2}$ for 30 min at room temperature to block endogenous peroxidase activity. After incubation in blocking buffer, sections were first incubated overnight with primary antibodies at $4^{\circ} \mathrm{C}$ and then with secondary biotin-conjugated antibodies for $60 \mathrm{~min}$ at room temperature. After washing with PBS-T, the sections were incubated with the avidin-biotin-peroxidase complex (Vectastain Elite ABC kit; Vector Laboratories) for $60 \mathrm{~min}$ at room temperature. The immune complexes were visualized by immersing the sections in $0.05 \%$ $\mathrm{DAB} / 0.015 \% \mathrm{H}_{2} \mathrm{O}_{2}$.

\section{Expression of Sulf Proteins in CHO-K1 Cells}

A DNA fragment encoding the full open reading frame was amplified by PCR using mouse Sulf 2 cDNA (GenBank ${ }^{\mathrm{TM}}$ accession No. NM_001252579) as a template. PCR was performed using the KAPA Taq Extra PCR kit (Kapa Biosystems). The forward and reverse primers were as follows: forward $5^{\prime}$-GATCTCGAGGCCACCATGGCACCCCCTGGC- $3^{\prime}$ and reverse $5^{\prime}$-AGTGGATCCTTAGCCTTCCCAACCTTCCCA-3'. The conditions for denaturation, annealing, and extension of the template cDNA were as follows: $94^{\circ} \mathrm{C}$ for $30 \mathrm{~s}, 60^{\circ} \mathrm{C}$ for $30 \mathrm{~s}$, and $72^{\circ} \mathrm{C}$ for $2 \mathrm{~min}$ for 35 cycles. The mouse Sulf- 2 cDNA PCR product was digested with $X h o I$ and BamHI restriction enzymes and subcloned into the corresponding site of the pAcGFP1-N2 vector (Clontech). Chinese hamster ovary $(\mathrm{CHO})-\mathrm{K} 1$ cells $\left(1 \times 10^{6}\right)$ were grown in 6 -cm dishes and transfected with $2 \mu \mathrm{g}$ pcDNA3.1/His-Sulf1 [26] and/or pAcGFP1-N2/Sulf2 using Lipofectamine ${ }^{\mathrm{TM}} 2000$ transfection reagent (Life Technologies) according to the manufacturer's instructions. DNA $(2 \mu \mathrm{g})$ in $250 \mu \mathrm{L}$ of Opti-MEM ${ }^{\mathrm{TM}}$ reduced serum medium without serum (Life Technologies) and Lipofectamine ${ }^{\mathrm{TM}} 2000$ in the same solution were mixed together and incubated for $20 \mathrm{~min}$ at room temperature. The mixture was added to the cells in culture dishes and incubated at $37^{\circ} \mathrm{C}$ under $5 \% \mathrm{CO}_{2}$. After $4 \mathrm{~h}$ of incubation, medium was replaced with F12 medium (Gibco) containing $10 \%$ FBS for $24 \mathrm{~h}$, then the medium was changed to Opti-MEM. Cells were allowed to grow for an additional $24 \mathrm{~h}$ before the medium was collected.

\section{Western Blot Analysis}

Medium from Sulf1- and/or Sulf2-transfected CHO-K1 cells was concentrated using Amicon Ultra- 4 centrifugal filter devices (Millipore) and centrifuging for $5 \mathrm{~min}$ at 3,000 g. Enriched medium $(\mathrm{EM} ; 20 \mu \mathrm{L})$ was separated by electrophoresis on $10 \%$ SDS polyacrylamide reducing gels. After transferring to an ImmobilonP membrane (Millipore), the membrane was incubated in blocking buffer containing $1 \%$ BSA in TBST at room temperature then incubated overnight at $4^{\circ} \mathrm{C}$ with a primary antibody. The membrane was further incubated with a secondary antibody in blocking buffer at room temperature for $1 \mathrm{~h}$. Signals were detected by chemiluminescence (ECL Plus, GE Healthcare) and visualized with an LAS-3000 Imaging System (Fuji film, Tokyo, Japan). Band intensity was quantified with ImageJ.

\section{Endoglucosamine-6-Sulfatase Assays for Sulf Activity}

The procedure described by Morimoto-Tomita et al. [26] was adapted for these assays. EM from transfected $\mathrm{CHO}-\mathrm{K} 1$ cells (pcDNA3.1 + pAcGFP-N2, pcDNA3.1/Sulf1-His + pAcGFP-N2, pcDNA3.1 + pAcGFP-N2/Sulf2, pcDNA3.1/Sulf1-His + pAcGFP$\mathrm{N} 2 / \mathrm{Sulf} 2$ : each in a total DNA weight of $2 \mu \mathrm{g}$ ) was prepared as described above. The standard reaction mixture contained $1.25 \mu \mathrm{mol}$ of Tris- $\mathrm{HCl}$ ( $\mathrm{pH} 7.2$ ), $0.25 \mu \mathrm{mol}$ of $\mathrm{MgCl}_{2}, 0.075 \mu \mathrm{mol}$ of $\mathrm{CaCl}_{2}, 2.5$ $\mu \mathrm{g}$ of porcine intestinal heparin (Sigma-Aldrich), and $20 \mu \mathrm{L}$ of EM in a total volume of $25 \mu \mathrm{L}$. Under these conditions, Sulf activity 
showed a linear relationship with incubation time up to $8 \mathrm{~h}$ (data not shown). Therefore, we treated heparin for $4 \mathrm{~h}$ with Sulf-EM to determine sulfatase activity in the collected Sulf-EM. After incubation at $37^{\circ} \mathrm{C}$ for 0 or $4 \mathrm{~h}$, the reaction was stopped by heating at $100^{\circ} \mathrm{C}$ for $5 \mathrm{~min}$. A mixture of $0.1 \mathrm{mIU}$ of heparinase I (Sigma), $0.025 \mathrm{mIU}$ of heparinase II (Sigma), and $0.01 \mathrm{mIU}$ of heparinase III (Santa Cruz) in $2 \mu \mathrm{L}$ from a total of $20 \mu \mathrm{M}$ Tris- $\mathrm{HCl}, \mathrm{pH} 7.2$, was added into the reaction mixture and incubated at $37^{\circ} \mathrm{C}$ for $3 \mathrm{~h}$. The digestion was stopped by heating at $100^{\circ} \mathrm{C}$ for $5 \mathrm{~min}$, and the mixture was filtered by centrifugation in an Ultrafree-MC filter (Millipore). Disaccharides generated by heparinase digestion were then analyzed by reverse-phase ion-pair high-performance liquid chromatography (HPLC) (Gilson) with a UV detector on a COS-

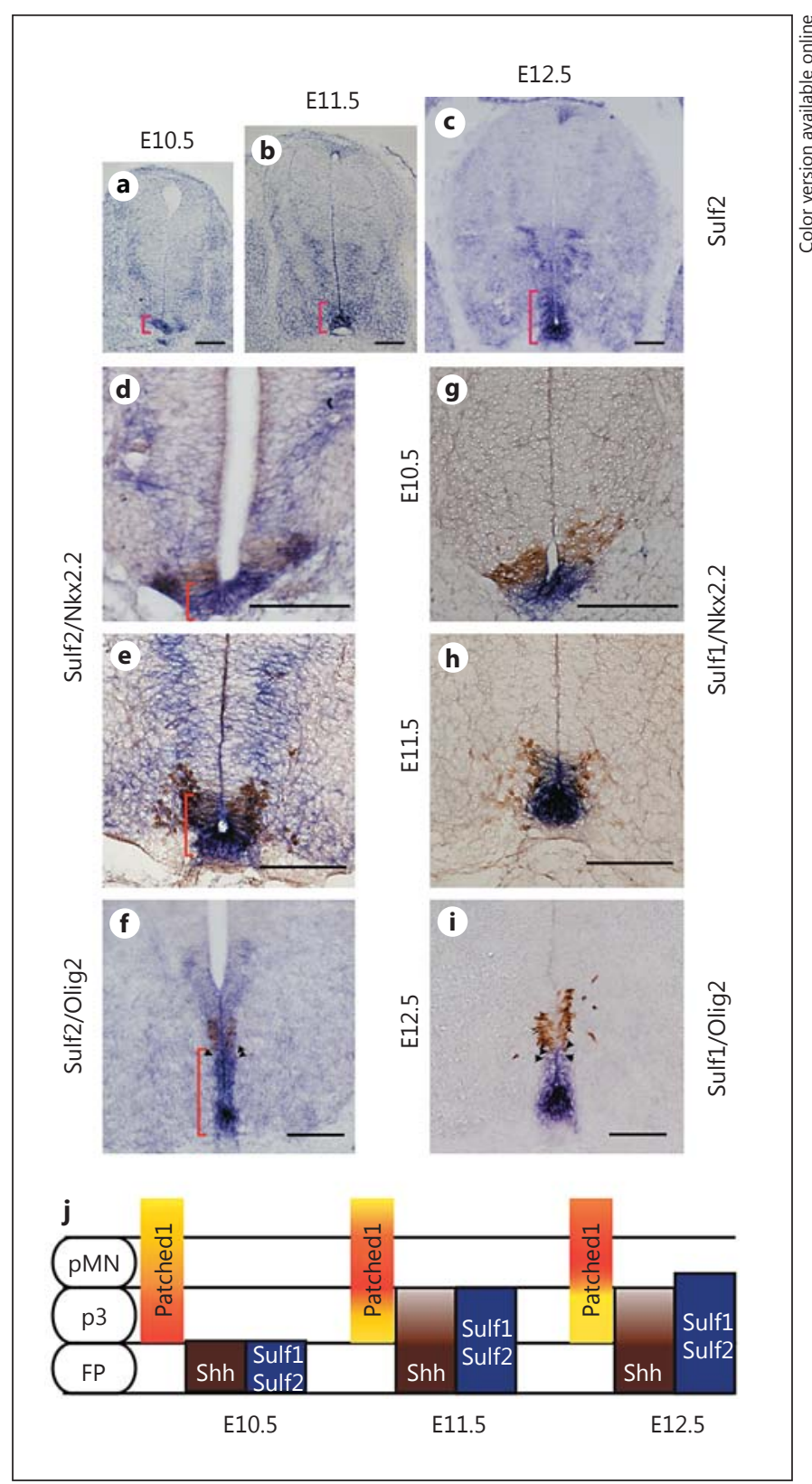

Dev Neurosci 2017;39:361-374

DOI: $10.1159 / 000464284$
MOSIL 5C18-MS-II column (Nacalai Tesque, Kyoto, Japan) run at $41{ }^{\circ} \mathrm{C}$. Disaccharides were eluted from the column as follows: time $0-28 \mathrm{~min}, 1.2 \mathrm{mM}$ tetrabutylammonium hydrogen sulfate (TAHS), 8.5\% acetonitrile, and $\mathrm{NaCl}$ gradient from 2 to $106 \mathrm{mM}$; time $28-37 \mathrm{~min}, 1.2 \mathrm{~mm}$ TAHS, $8.5 \%$ acetonitrile, and $106 \mathrm{~mm}$ $\mathrm{NaCl}$; and time $37-60 \mathrm{~min}, 1.2 \mathrm{~mm}$ TAHS, $8.5 \%$ acetonitrile, and $2 \mathrm{mM} \mathrm{NaCl}$. Absorbance at $232 \mathrm{~nm}$ was monitored to detect the disaccharide double bonds, and components were identified by comparison with authentic unsaturated disaccharide markers (i.e., $\Delta$ DiHS-0S, $\Delta$ DiHS-(N,6)diS, $\Delta$ DiHS-(N,2)diS, DiHS-(N,6,2)triS, DiHS-2S, $\Delta$ DiHS-6S, and $\Delta$ DiHS-NS; Sigma).

\section{Statistics}

Statistical analysis was performed via a one-way ANOVA followed by Dunnett post hoc comparison. Significance was determined at $p<0.05$. Data represent the average of at least 3 independent experiments.

\section{Results}

\section{Concurrent Changes in Sulf1 and Sulf2 Expression}

Patterns during Mouse Spinal Cord Development

To investigate the relationship between Sulf1 and Shh signaling in the embryonic mouse spinal cord, we compared Sulf1, Shh, and Patched1 expression patterns, the Shh receptor, and reporter of Shh signaling activity [4] in wild-type (WT) embryonic spinal cord from E10.5 to E12.5. At E10.5, Sulf1-mRNA and Shh-mRNA were expressed in the floor plate, ventral to the 33 domain marked by Nkx2.2 (online suppl. Fig. 1a, b, d; for all online suppl. material, see www.karger.com/doi/10.1159/000464284).

Fig. 1. Expression pattern of Sulf1 and Sulf 2 during development of the mouse spinal cord. Transverse sections from E10.5 (a, d, g), E11.5 (b, e, h), and E12.5 (c, f, i) spinal cord tissues were subjected to in situ hybridization with Sulf1 (g-i) and Sulf2 (a-f) RNA probes, and immunohistochemistry with an anti-Nkx2.2 antibody (d, e, g, h) and an anti-Olig2 antibody (f, i). Sulf2 expression was widely distributed throughout the ventral spinal cord and could be divided into regions of strong (red brackets) and weak expression (a-c, f). $\mathbf{d}-\mathbf{i}$ The expression of Sulf1 ( $\mathbf{g}-\mathbf{i})$ was mapped along with the region of strong Sulf2 expression (d-f) using the p3 domain marker Nkx2.2 and the pMN domain marker Olig2. At E10.5, strong Sulf2 expression was restricted to the floor plate, ventral to the $\mathrm{p} 3$ domain marked by Nkx2.2, and the region lateral to the $\mathrm{p} 3$ domain (d). At E11.5, Sulf2 expression expanded into the p3 domain (e). At E12.5, Sulf2 expression partly overlapped with the pMN domain marked by Olig2. Arrowheads indicate Sulf $2+\mathrm{Olig} 2+$ cells (f) and Sulf1+Olig2 + cells (i). The region of strong Sulf2 expression (red brackets; d-f) entirely overlapped with the Sulf1 expression pattern (g-i). Scale bars, $100 \mu \mathrm{m}(\mathbf{a}-\mathbf{i})$. j Schematic drawing showing the Sulf1, strong Sulf2, Shh, and Patched1 expression patterns. The strong Sulf2 expression pattern was similar to that of Sulf1.

\section{Jiang et al.}


In contrast, Patched 1 was strongly expressed in the $\mathrm{p} 3$ domain dorsal to the floor plate, where Shh and Sulf1 were expressed, and less intense throughout the spinal cord (online suppl. Fig. 1c). At E11.5, the Sulf1- and Shhexpressing region expanded into the $\mathrm{p} 3$ domain, ventral to the pMN domain marked by Olig2 (online suppl. Fig. 1e, f, h). Simultaneously, the strong Patched 1 signal shifted dorsally from the $\mathrm{p} 3$ domain at E10.5 to the pMN domain at E11.5 (online suppl. Fig. 1g). At E12.5, Shh was still expressed in the p3 domain, although the strong Patched 1 signal shifted further dorsally compared to the pattern at E11.5 (online suppl. Fig. 1j, k). Moreover, we found that Sulf1 expression was also slightly extended dorsally and was colocalized in cells weakly positive for Olig2, although those double-positive cells are restricted to the ventral region of the $\mathrm{pMN}$ domain and are composed of a very small population of Olig2+ cells (online suppl. Fig. 1i). Overall, these results are consistent with the observations in zebrafish [30] and strongly suggest a conserved mechanism of Shh signaling regulation between both species.

In addition to Sulf1, another member of the HS sulfatase family, Sulf2, is expressed in the embryonic mouse central nervous system [31] and is known to be involved in tumorigenesis [35-37]. However, the expression pattern of Sulf2 in the mouse spinal cord and its potential role in spinal cord development has yet to be characterized. Thus, we investigated Sulf2 expression in the mouse spinal cord from E10.5 to E12.5. Sulf2 expression was widely distributed in the ventral spinal cord, which could be divided into 2 regions based on either weak or strong Sulf2 signals (Fig. 1a-c). The ventricular zone (VZ) strongly expressed Sulf2, similar to the pattern of Sulf1 expression (online suppl. Fig. 1a, e, i). Thus, we used Nkx2.2 and Olig2 antibodies to map the position of the VZ region that strongly expressed Sulf2. At E10.5, the strong expression of Sulf 2 was restricted to the floor plate and the region lateral to the $\mathrm{p} 3$ domain (Fig. 1d). At E11.5, it expanded into the p3 domain (Fig. 1e), and by E12.5, strong expression of Sulf2 could also be observed in a ventral region of the pMN domain, although the relatively weaker expression was seen widely in the more dorsal region (Fig. 1f). These results showed that the region of strong Sulf2 expression almost completely overlapped with the Sulf1 expression domain (Fig. 1g-i).

Taken together, the expression patterns of Sulf1, Sulf2, Shh, and Patched 1 suggest that strong Shh signaling may be induced by the release of Shh through Sulf1 and Sulf2 activity as it spreads into the neighboring dorsal region. This strong Shh signaling may, in turn, induce further Shh and Sulf expression. The MN-to-OPC fate switch is known to occur between E11.5 and E12.5 and is induced by strong Shh signaling $[12,13,29]$. These results suggest that the strong Shh signaling acting on the pMN domain is generated by the coordinated action of Shh and Sulf1/2, similar to the mechanism found in zebrafish, although the involvement of Sulf2 in zebrafish has not been addressed.

\section{Inability of Sulf2 to Compensate for the Loss of Sulf1 Activity in Sulf1 KO Mice}

In the study by Touahri et al. [12], OPC generation was delayed, and MN generation was prolonged in Sulf1 KO mice. Given that our results above showed an overlapping
Fig. 2. Sulf2 or Sulf1 expression pattern in Sulf1 KO or Sulf2 KO mice. a-d Transverse sections from E12.5 Sulf1 KO mouse spinal cord tissue were subjected to in situ hybridization with a Sulf2 RNA probe and immunohistochemistry with an anti-Sulf2 antibody. There were no differences in the Sulf2 expression pattern between WT $(\mathbf{a}, \mathbf{c})$ and Sulf1 KO (b, d) mice at both the mRNA (a, b) and protein (c, d) level. e-h Transverse sections from E12.5 Sulf2 KO mouse spinal cord tissue were subjected to in situ hybridization with a Sulf1 RNA probe and immunohistochemistry with an anti-Sulf1 antibody. There were no differences in the Sulf1 expression pattern between WT $(\mathbf{e}, \mathbf{g})$ and Sulf2 KO (f, h) mice at both the mRNA $(\mathbf{e}, \mathbf{f})$ and protein $(\mathbf{g}, \mathbf{h})$ level. Scale bars, $100 \mu \mathrm{m}$.

Sulfatase Modulation of Shh Gradient during MN-to-OPC Cell Fate Change

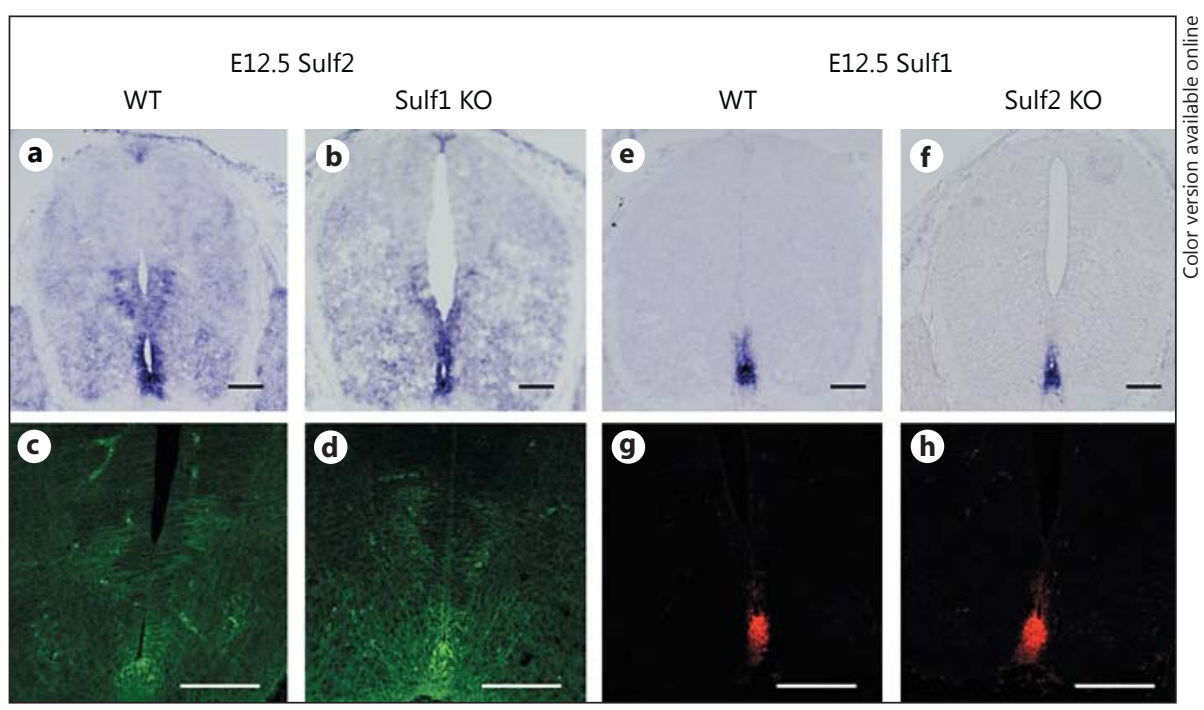

Dev Neurosci 2017;39:361-374 DOI: $10.1159 / 000464284$ 
Table 1. Sulfatase (Sulf) activity expressed in CHO-K1 cells

\begin{tabular}{|c|c|c|c|}
\hline & Sulf1-EM & Sulf2-EM & Sulf1/2-EM \\
\hline Actual Sulf activity, pmol/h/20 $\mu \mathrm{L}$ & 18 & 19 & 28 \\
\hline Protein content & Sulf1 $170 \%$ & Sulf2 $120 \%$ & $\begin{array}{l}\text { Sulf1 } 100 \% \\
\text { Sulf2 } 100 \%\end{array}$ \\
\hline Theoretical Sulf activity, pmol/h/relative protein content & 11 & 16 & 27 \\
\hline
\end{tabular}

Enriched medium (EM) from Sulf1-expressing cells contained 1.7 times more Sulf1 protein than EM from Sulf1/2-expressing cells in Western blotting (online suppl. fig. 2). EM from Sulf2-expressing cells contained 1.2 times more Sulf2 protein than EM from Sulf1/2-expressing cells in Western blotting (online suppl. fig. 2).

expression pattern for Sulf1 and Sulf2 in the developing mouse spinal cord, it raised the question as to why Sulf2 cannot compensate for the loss of Sulf1 activity in Sulf1 KO mice. It is possible that the loss of Sulf1 might affect Sulf2 expression, but the expression of Sulf2 mRNA (Fig. 2a, b) and protein (Fig. 2c, d) in Sulf1 KO and WT mice was unchanged.

Another possible scenario is that an interaction between Sulf1 and Sulf2 proteins is necessary for their sulfatase activity. In the Sulf1 KO mouse, Sulf 2 protein alone may not be sufficient for full sulfatase activity in the developing spinal cord. To assess this possibility, we performed an in vitro assay for sulfatase activity. Media from Sulf1-, Sulf2-, or double-transfected CHO-K1 cells were collected and enriched as described in the methods. To evaluate sulfatase activity, heparin was used as a substrate. After in vitro treatment of heparin with Sulf1/2-EMs, the heparin was digested with a mixture containing heparinase, and the disaccharide products were analyzed by HPLC [26]. The results of the sulfatase activity assay (Table 1) showed that sulfatase activity in EM from Sulf1-expressing CHO$\mathrm{K} 1$ cells was $18 \mathrm{pmol} / \mathrm{h} / 20 \mu \mathrm{L}$, from Sulf2-expressing cells $19 \mathrm{pmol} / \mathrm{h} / 20 \mu \mathrm{L}$, and from Sulf1/2-expressing cells 28 $\mathrm{pmol} / \mathrm{h} / 20 \mu \mathrm{L}$. EM from Sulf1-expressing cells contained 1.7 times more Sulf1 protein than EM from Sulf1/2-expressing cells in Western blotting (online suppl. Fig. 2). EM from Sulf2-expressing cells contained 1.2 times more Sulf2 protein than EM from Sulf1/2-expressing cells in Western blotting (online suppl. Fig. 2). After normalizing to protein content, sulfatase activity was $11 \mathrm{pmol} / \mathrm{h} / \mathrm{rela}$ tive protein concentration for Sulf1 alone and $16 \mathrm{pmol} / \mathrm{h} /$ relative protein concentration for Sulf2 alone. Combined Sulf1 and Sulf 2 activity was $27 \mathrm{pmol} / \mathrm{h} /$ relative protein concentration, which was very close to the activity level of $28 \mathrm{pmol} / \mathrm{h} /$ relative protein concentration in double-expressing cells. Thus, we conclude that no significant interaction is required between Sulf1 and Sulf2 to exert their full sulfatase activity. This also suggests that in the absence of Sulf1, total sulfatase activity is not sufficient to exert strong Shh signaling on the pMN domain, resulting in the delayed MN-to-OPC switch in Sulf1 KO mice. In addition, we found that Shh expression in Sulf1 KO mice remained restricted to the floor plate, even at E11.5 and E12.5 (Fig. 3b, e), whereas the WT mouse exhibited dorsal expansion into the $\mathrm{p} 3$ domain (Fig. 3a, d). This supports the hypothesis that Sulf1 or Sulf2 activity alone is insufficient to induce Shh in the p3 domain or for strong Shh signaling input into the $\mathrm{pMN}$ domain. Moreover, if this hypothesis is correct, Sulf2 KO mice should have a similar phenotype to Sulf1 KO mice. To confirm this, we analyzed Sulf2 KO mice and, as expected, Shh and Patched 1 expression differed from that of WT mice at E11.5 and E12.5 (Fig. 3c, f, g, i, j, l) and was similar to the Sulf1 KO (Fig. 3b, $\mathrm{e}, \mathrm{h}, \mathrm{k})$. In E11.5 WT spinal cord, the strong expression of Patched1 was observed in the pMN domain (Fig. 3g), which disappeared and began to demonstrate homogeneous expression through the dorsoventral axis by E12.5 (Fig. 3j). In Sulf1 or Sulf2 KO spinal cord, however, less strong expression of Patched 1 in the $\mathrm{pMN}$ domain was detected at E11.5 compared to that in WT (Fig. 3g, h, i). The strong Patched 1 expression in the pMN domain appeared at E12.5 instead of E11.5 (Fig. 3k, 1) in Sulf1 KO and Sulf2 $\mathrm{KO}$ mice, indicating a potential delay in the accumulation of Shh signaling in the pMN domain. On the other hand, the expression of Sulf1 mRNA (Fig. 2e, f) and protein (Fig. 2g, h) in Sulf2 KO and WT mice was unchanged. To further confirm this hypothesis, we next analyzed domain formation and cell differentiation in the spinal cord of Sulf2 KO mice.

Both the $p 3$ and $p M N$ Domains Are Shifted Ventrally in E12.5 Sulf2 KO Mice

During spinal cord development, once progenitor domain formation is complete, maintenance of the domains
366

Dev Neurosci 2017;39:361-374 DOI: $10.1159 / 000464284$
Jiang et al. 
Fig. 3. Impaired expression pattern of Shh and Shh signaling in Sulf1 KO and Sulf2 $\mathrm{KO}$ mice at E11.5 and E12.5. a-f Transverse sections of embryonic spinal cords were subjected to in situ hybridization and immunohistochemistry with an Shh RNA probe and an anti-Olig2 antibody at E11.5 $(\mathbf{a}-\mathbf{c})$ and E12.5 (d-f). In WT mice (a, d), Shh expression was expanded into the $\mathrm{p} 3$ domain, ventral to the $\mathrm{pMN}$ domain marked by Olig2. In Sulf1 KO (b, e) and Sulf2 KO (c, f) mice, Shh expression was restricted to the floor plate and did not expand into the p3 domain. g-I Transverse sections of embryonic spinal cords were subjected to in situ hybridization using a Patched1 RNA probe. Patched1 expression showed a similar pattern between WT (g) and Sulf1 KO (h) or Sulf2 KO (i) mice at E11.5, with enhanced signals in the $\mathrm{pMN}$ domain. The Patched 1 signal in the $\mathrm{pMN}$ domain was weaker in the Sulf1 $\mathrm{KO}$ (h) and Sulf2 KO (i) mice than in WT $(\mathbf{g})$ mice at E11.5. At E12.5, while the strong Patched1 signal accumulation in the pMN domain disappeared in WT mice $(\mathbf{j})$, the Patched 1 expression pattern in Sulf1 $\mathrm{KO}(\mathbf{k})$ and Sulf2 KO (I) mice was similar to that at E11.5, with the strong signal accumulation in the pMN domain maintained. Red brackets indicate the pMN domain. Scale bars, $100 \mu \mathrm{m}$.

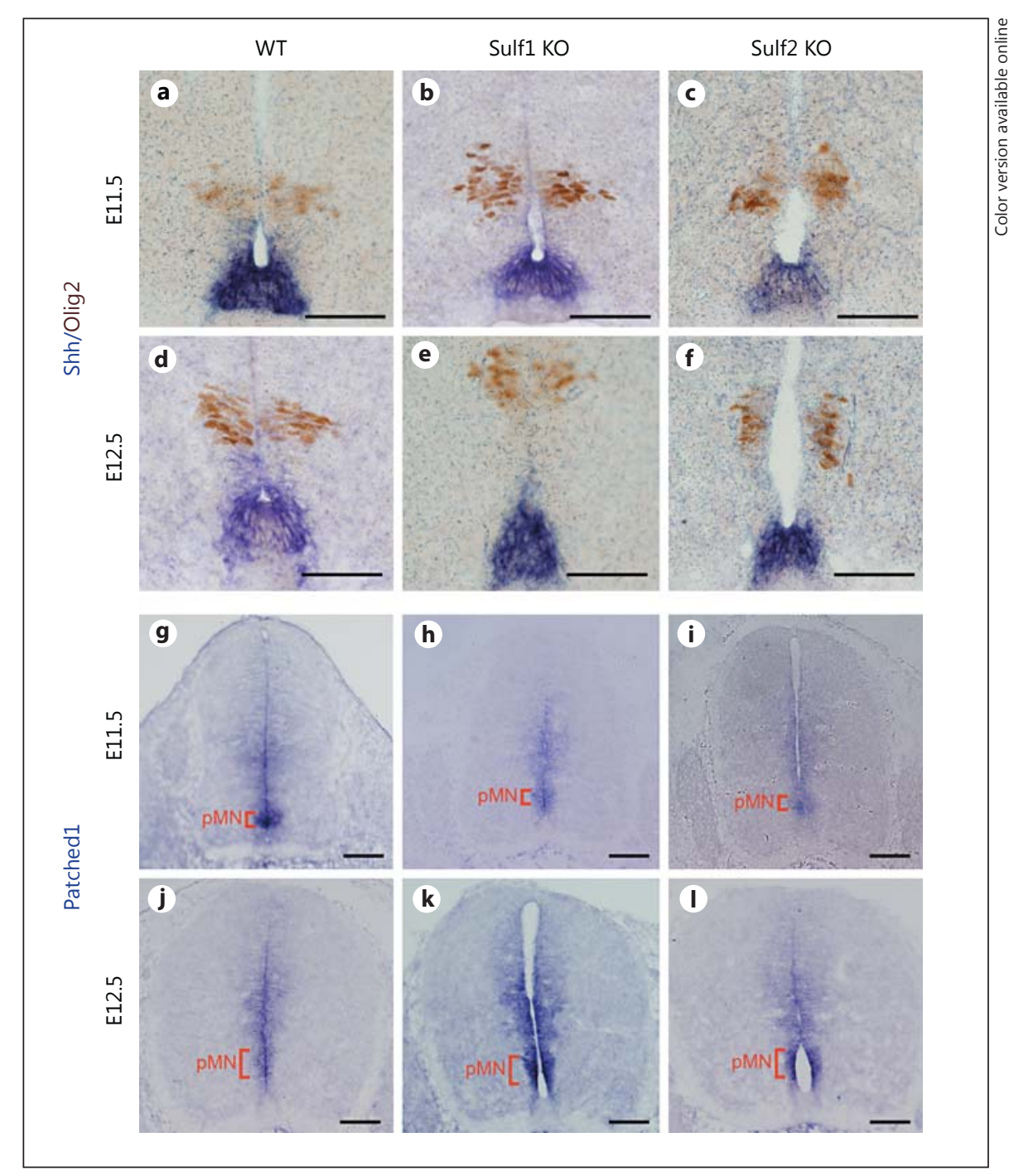

is Shh independent [38], although the expansion of the $\mathrm{Nkx} 2.2+$ region into the $\mathrm{pMN}$ domain is dependent on the concentration of Shh, resulting in the generation of Olig2+Nkx2.2+ cells at E12.5 [10]. We examined domain positioning within the dorsoventral axis in the spinal cord of Sulf1 KO and Sulf2 KO mice at E12.5. We performed in situ hybridization using Math 1 and Pax7 RNA probes as markers of the dorsal domains, and immunohistochemistry with Olig2 and Nkx2.2 antibodies to mark the ventral domains. At E12.5, the position of the dorsal domains in Sulf1 KO and Sulf2 KO mice did not differ from that of WT mice (Fig. 4a-f). However, the p3 domain (Nkx2.2+ region) and the pMN domain (Olig2+ region) were shifted ventrally within the spinal cord (Fig. $4 \mathrm{~g}-\mathrm{i}$ ). We quantified the ratio of the length of each domain to the total length of the spinal cord from the floor plate to

Sulfatase Modulation of Shh Gradient during MN-to-OPC Cell Fate Change the roof plate. While the pMN domain was shifted ventrally, its length did not change (WT $=0.11 \pm 0.004, n=$ 5 ; Sulf1 KO $=0.11 \pm 0.002, n=3$; Sulf2 $\mathrm{KO}=0.11 \pm 0.004$, $n=4)$. In addition, the $\mathrm{p}^{*}$ domain, which corresponds to the Olig2 and Nkx2.2 double-positive area, also showed no remarkable change (WT $=0.048 \pm 0.005, n=5$; Sulf1 $\mathrm{KO}=0.047 \pm 0.008, n=3$; Sulf $2 \mathrm{KO}=0.04 \pm 0.007, n=$ 4). On the other hand, the p3 domain was also shifted ventrally, and its length was significantly decreased $(\mathrm{WT}=0.17 \pm 0.01, n=5$; Sulf1 $\mathrm{KO}=0.14 \pm 0.04, n=3$; Sulf2 KO $=0.13 \pm 0.03, n=4$; Fig. $4 \mathrm{j})$.

\section{Abnormal OPC and MN Differentiation in Sulf2 KO Mice at E12.5}

Next, we examined the differentiation of progenitor cells in the pMN domain. We quantified the number of

Dev Neurosci 2017;39:361-374 DOI: $10.1159 / 000464284$ 
Fig. 4. Ventral shift of spinal cord structural domains at E12.5 in Sulf1 KO and Sulf2 KO mice. Transverse sections from E12.5 spinal cord tissue were subjected to in situ hybridization with Math1 (a-c) and Pax7 (d-f) RNA probes to identify the dorsal domains, and double immunostaining with an anti-Olig2 antibody and anti-Nkx2.2 antibody $(\mathbf{g - i})$ to identify the ventral domains. Arrowheads indicate Math1+ areas. At E12.5, the positions of the dorsal domains in the Sulf1 KO (b, e) and Sulf2 KO $(\mathbf{c}, \mathbf{f})$ mice did not differ from that in WT mice (a, d), but the $\mathrm{p} 3$ domain $(\mathrm{Nkx} 2.2+$ region, green) and the $\mathrm{pMN}$ domain (Olig2+ region, magenta) were shifted ventrally in the ventral spinal cord $(\mathbf{g}-\mathbf{i})$. Dorsal end of the pMN domain position in WT and Sulf1 KO or Sulf2 KO mice was indicated by the yellow and white dotted lines, respectively. Scale bars, $100 \mu \mathrm{m}$. j Illustration showing the proportional length of each domain to the total length of the spinal cord from the floor plate to the roof plate. Notably, the position of the p3 and the pMN domains were clearly shifted ventrally in Sulf1 KO and Sulf2 KO mice.

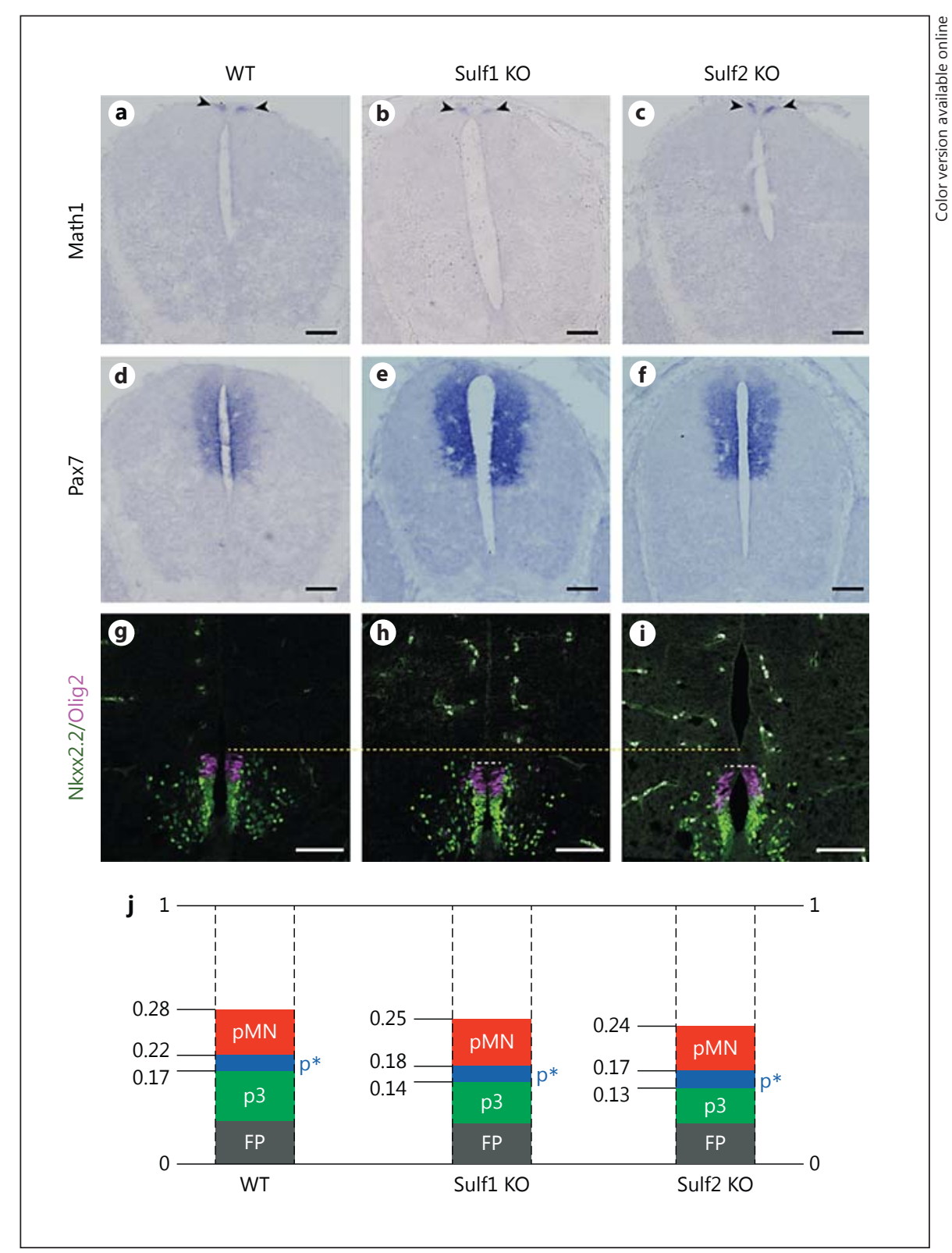

OPCs by in situ hybridization using a platelet-derived growth factor receptor $\alpha$ (PDGFR $\alpha$ ) RNA probe as an OPC marker and quantified the number of MNs by immunostaining with an Islet1/2 antibody as a marker of MNs at E12.5 in Sulf1 KO and Sulf2 KO mice. In both, the Sulf1 KO and Sulf2 KO mice, the number of PDGFR $\alpha+$ cells was significantly reduced compared to WT mice $(\mathrm{WT}=15 \pm 2.7, n=11$; Sulf1 $\mathrm{KO}=6 \pm 1.2, n=12$; Sulf2 $\mathrm{KO}=4 \pm 0.8, n=11$; Fig. $5 \mathrm{a}-\mathrm{c}, \mathrm{g})$. In the ventral horn of the spinal cord, there are two types of mature MNs: autonomic MNs (AMNs) and somatic MNs (SMNs) [39].
We found no significant difference in the number of SMNs between WT and Sulf1 KO or Sulf2 KO mice at $\mathrm{E} 12.5(\mathrm{WT}=120 \pm 4.1, n=4$; Sulf1 $\mathrm{KO}=114 \pm 5.6, n=$ 4; Sulf2 KO $=124 \pm 5.3, n=4$; Fig. $5 \mathrm{~d}-\mathrm{f}$, i), however, the number of AMNs was significantly increased in both the Sulf1 KO and Sulf2 KO mice (WT $=32 \pm 2.9, n=4$; Sulf1 $\mathrm{KO}=50 \pm 3.2, n=4$; Sulf2 $\mathrm{KO}=55 \pm 6.1, n=4$; Fig. $5 \mathrm{~d}-$ $f, h)$.

Together, these results suggest that the MN-to-OPC fate switch is impaired in Sulf2 KO mice, similar to that previously shown in Sulf1 KO mice [12]. 


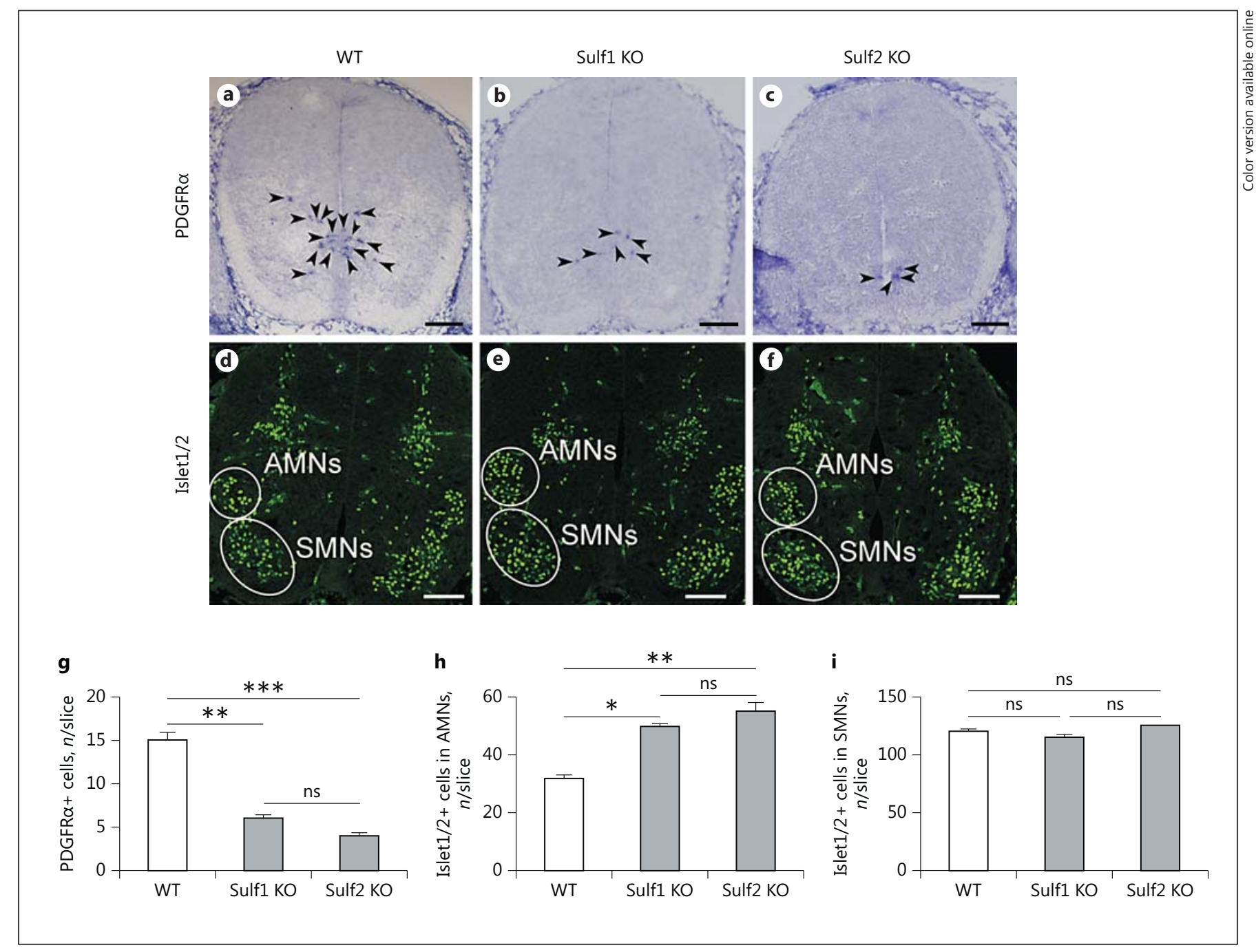

Fig. 5. Reduced OPC generation and increased MN generation at E12.5 in Sulf1 KO and Sulf2 KO mice. a-f Transverse sections from E12.5 spinal cord tissue were subjected to in situ hybridization with a PDGFRa RNA probe (a-c) as an OPC marker and immunostaining with an Islet1/2 antibody (d-f) as an MN marker. a-c In WT mice (a), PDGFR $a+$ cells appeared from the pMN domain and migrated out into the ventral spinal cord. In Sulf1 KO (b) and Sulf2 KO (c) mice, the numbers of PDGFRa + cells were remark-

\section{Sulf2 Is Required for the Precise MN-to-OPC Fate}

Switch in the PMN Domain

It is well known that OPCs are generated from Olig2+Nkx2.2+ cells [10], thus we aimed to determine whether the decreased OPC generation in Sulf1 KO and Sulf2 KO mice was caused by a defect in Olig2+Nkx2.2+ cell generation. Therefore, we performed Olig2/Nkx2.2 double immunostaining. As expected, the number of Olig2+Nkx2.2+ cells in Sulf1 (Fig. 6c, d) and Sulf2 (Fig. 6e, ably reduced. Arrowheads indicate PDGFRa+ cells. The number of SMNs was normal in Sulf1 KO (e) and Sulf2 KO (f) mice, but the number of AMNs was significantly increased. White circles indicate AMNs and SMNs. Scale bars, $100 \mu \mathrm{m}$. $\mathbf{g}$ Quantification of the number of PDGFRa + cells. $\mathbf{h}, \mathbf{i}$ Quantification of the number of Islet $1 / 2+$ cells in the AMNs and SMNs. Results are presented as mean numbers of cells \pm SEM. ${ }^{*} p<0.05,{ }^{* *} p<0.01,{ }^{* * *} p<0.001$. ns, no significance. b) mice $(\mathrm{WT}=23 \pm 1.2, n=3$; Sulf1 $\mathrm{KO}=16 \pm 1.0, n=6$; Sulf2 $\mathrm{KO}=17 \pm 0.7, n=6$; Fig. $6 \mathrm{~g}$ ). These results suggest that a decrease in the number of Olig $2+\mathrm{Nkx} 2.2+$ cells contributes to the reduced OPC generation in Sulf1 KO and Sulf2 KO mice at E12.5.

We next examined Ngn2 expression in the pMN domain because Ngn2 expression is required for MN generation from the pMN domain, and downregulation of Ngn2 


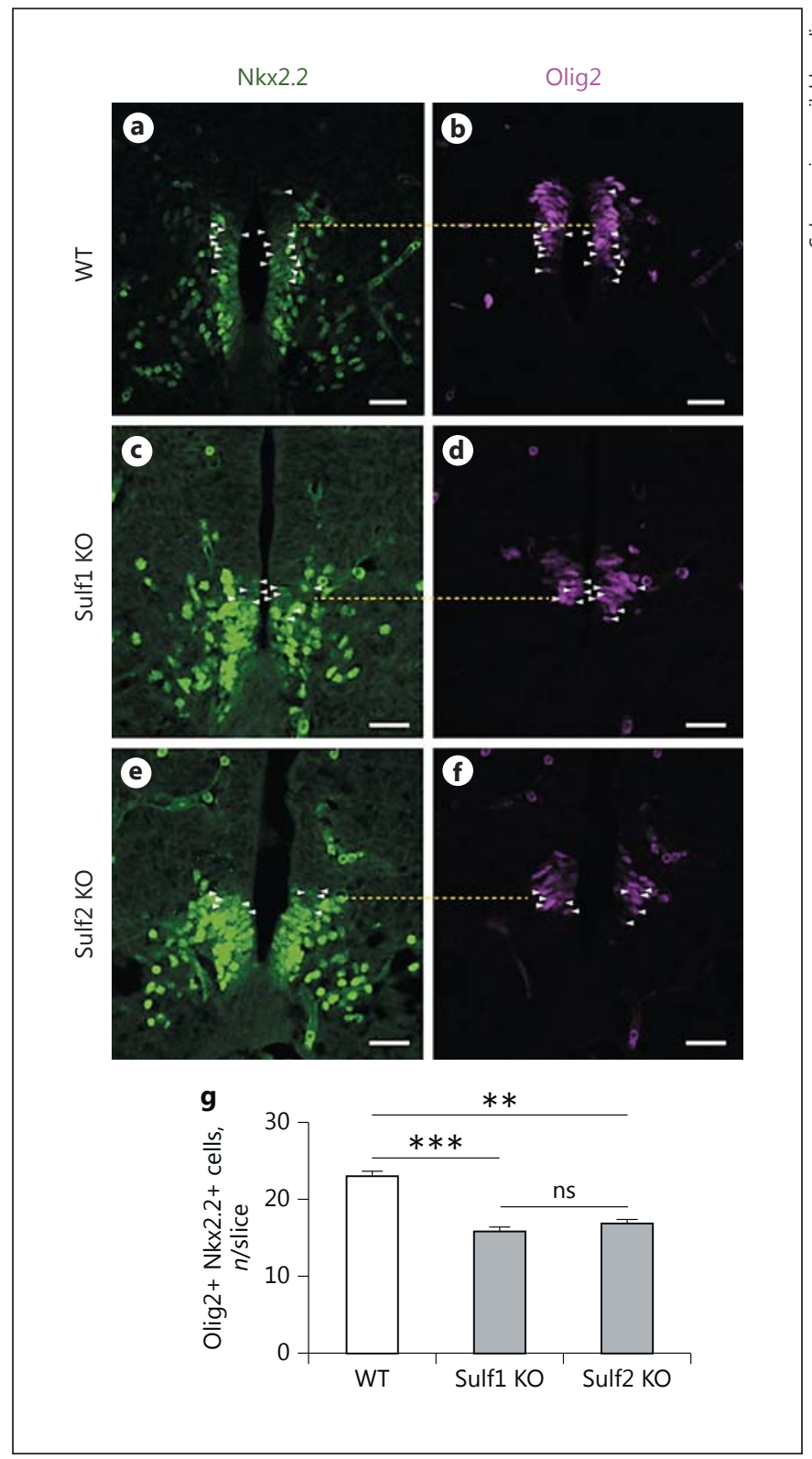

Fig. 6. Decreased numbers of Olig2+Nkx2.2+ cells in Sulf1 KO and Sulf2 KO mice at E12.5. a-f Double immunostaining of transverse sections for Nkx2.2 (green) and Olig2 (magenta) at E12.5 in WT (a, b), Sulf1 KO (c, d), and Sulf2 KO (e, f) mice. Olig2+Nkx2.2+ cells (Nkx2.2+ cells above the yellow dotted lines) in the Sulf1 KO (c, d) and Sulf2 $\mathrm{KO}(\mathbf{e}, \mathbf{f})$ mice were reduced compared to WT mice (a, b). Arrowheads indicate Olig2+Nkx2.2+ cells. Scale bars, 50 $\mu \mathrm{m} . \mathbf{g}$ Quantification of Olig2+Nkx2.2+ cells. Results are presented as mean numbers of cells \pm SEM. ${ }^{* *} p<0.01$, ${ }^{* * *} p<0.001$. ns, no significance. is involved in the MN-to-OPC fate switch. At E12.5, Ngn2 expression was still observed in the pMN domain of Sulf1 $\mathrm{KO}$ and Sulf2 KO mice (Fig. 7b, c), and the number of Ngn2+Olig2+ cells was significantly increased compared to WT (Fig. 7a) mice (WT $=5 \pm 0.6, n=3$; Sulf1 KO $=12 \pm$ $0.9, n=3$; Sulf2 $\mathrm{KO}=12 \pm 1.0, n=3$; Fig. 7j). Moreover, we found that the number of Islet $1 / 2+$ immature MNs emerging from the pMN domain (shown within the dotted square in Fig. $7 \mathrm{~d}-\mathrm{i}$ ) was significantly increased in Sulf1 $\mathrm{KO}$ and Sulf2 KO mice compared to WT mice (WT $=4 \pm 0.5, n=$ 6; Sulf1 KO $=7 \pm 0.5, n=5$; Sulf2 $\mathrm{KO}=7 \pm 0.2, n=4$; Fig. 7k). These results suggest that $\mathrm{MN}$ generation remains ongoing in Sulf1 KO and Sulf2 KO mice at E12.5.

In both the Sulf1 KO and Sulf2 KO mice, MN generation was prolonged and the MN-to-OPC fate switch was delayed at E12.5. These results demonstrate that not only Sulf1, but also Sulf2, is required for the precise MN-to$\mathrm{OPC}$ fate switch in the $\mathrm{pMN}$ domain.

\section{Sulfs Act as Positive Regulators of Shh and Shh}

Signaling to Accurately Regulate the MN-to-OPC Fate Switch

During mouse ventral spinal cord development, domain formation is dependent on both the concentration and duration of exposure to Shh $[5,7,40]$. Our results showed that Sulf2 KO mice have a similar phenotype to Sulf1 KO mice, which supports our hypothesis that Sulf1 or Sulf2 activity alone is not sufficient to induce Shh expression in the $\mathrm{p} 3$ domain and exert strong Shh signaling on the pMN domain. In other words, there is a threshold of sulfatase activity that is required to induce strong Shh signaling in the pMN domain, and sulfatase activity from Sulf1 or Sulf2 alone does not reach this threshold. To further confirm this hypothesis, we examined the phenotype of Sulf DKO and Sulf DHe mice. We found that both Sulf $\mathrm{DKO}$ and DHe mice showed phenotypic similarity to Sulf1 KO mice or Sulf2 KO mice, including the expression pattern of Shh and Patched1, domain formation, and MN and OPC generation (online suppl. Fig. 3, 4). It is noteworthy that the phenotype did not worsen in Sulf DKO mice, which again supports our threshold hypothesis and demonstrates that reduced sulfatase activity below the threshold level results in similar phenotypes.

\section{Discussion}

In the embryonic ventral spinal cord, Olig2 progenitors undergo a change in fate from $\mathrm{MN}$ generation to OPC generation [9]. Shh is essential for this fate change.
Jiang et al. 
Fig. 7. $\mathrm{MN}$ generation was prolonged in Sulf1 KO and Sulf2 KO mice at E12.5. a-c E12.5 transverse sections of embryonic spinal cords were subjected to in situ hybridization with an Ngn2 RNA probe and immunohistochemistry with an antiOlig2 antibody. Arrowheads indicate Ngn2+Olig2+ cells. d-i E12.5 transverse sections of the embryonic spinal cords were subjected to double immunostaining with an anti-Islet $1 / 2$ antibody and an antiOlig2 antibody. g-i White dotted square areas in $\mathbf{d - f}$ are shown at higher magnification. Arrowheads indicate immature MNs around the $\mathrm{VZ}$ of the $\mathrm{pMN}$ domain. Scale bars, $100 \mu \mathrm{m}$. j, k Quantification of Ngn2+Olig2+ cells $(\mathbf{j})$ and Islet $1 / 2+$ cells in the medial region $(\mathbf{k})$. Results are presented as mean numbers of cells \pm SEM. ${ }^{*} p<0.05$, ${ }^{* *} p<0.01,{ }^{* * *} p<0.001$. ns, no significance.

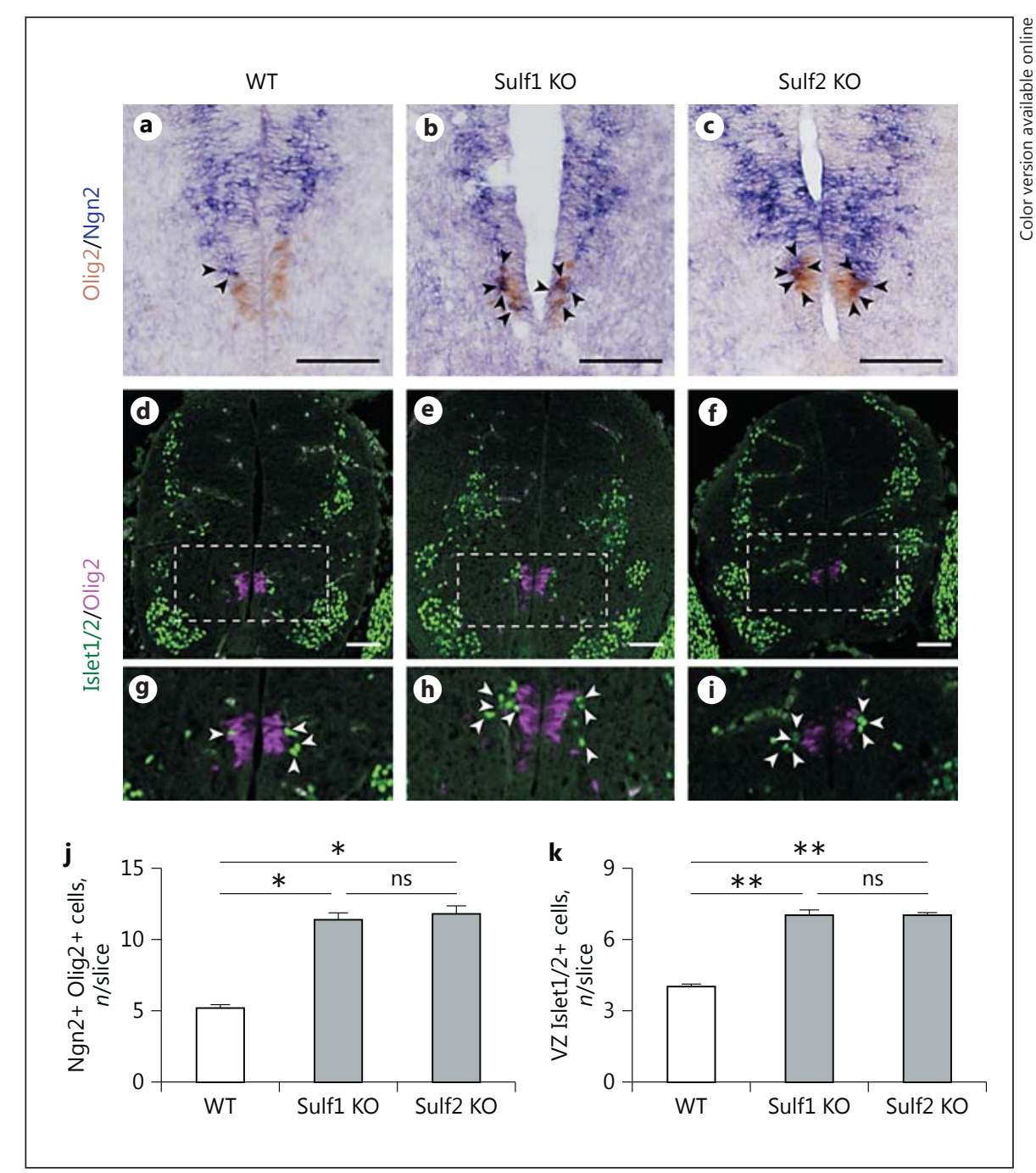

Our study demonstrated that Sulf2, an HS 6-O-sulfatase, is involved in regulating the $\mathrm{MN}$-to-OPC fate change in the mouse ventral spinal cord, similar to the role of Sulf1 [12], and the presence of both Sulf1 and Sulf2 is required for the precise MN-to-OPC fate switch. Moreover, our study suggests that in the mouse ventral spinal cord, the dorsal expansion of the sulfatase-expressing region (including both Sulf1 and Sulf2) is induced by strong Shh signaling, and these sulfatases regulate the MN-to-OPC fate switch by inducing strong Shh signaling in the $\mathrm{pMN}$ domain.

The secreted morphogen Shh organizes the pattern of cellular differentiation in the ventral spinal cord. During ventral spinal cord development, there are 2 phases of Shh signaling: cell fate specification during the early stage before E10.5 and cell type-specific differentiation during the

Sulfatase Modulation of Shh Gradient during MN-to-OPC Cell Fate Change later stage after E10.5 [16, 38, 41, 42]. Shh organizes cellular differentiation in the ventral spinal cord via multiple mechanisms, including transcriptional upregulation of Patched 1 , transcriptional downregulation of Gli, and differential stability of active and inactive Gli isoforms $[6,7]$. In addition, Shh signaling is essential for OPC generation at E12.5 $[15,16]$. Therefore, in the early phase, Shh is required for cell fate specification/domain formation of the ventral spinal cord, and later for the MN-to-OPC fate change.

Recent work in chicks and mice has pointed to a function for Sulf1 in regulating Shh signaling in Olig2+ progenitors to control the MN-to-OPC fate change in the pMN domain $[12,29]$. Moreover, in the zebrafish ventral spinal cord, Sulf1 expression follows Shh expression and promotes strong Shh signaling input to neighboring dor- 
sal cells [30]. Given that a previous report showed that QSulf1 (quail Sulf1) expression in developing neural tube is induced by Shh [43] and sulfatase expression (including the Sulf1-expressing region and strong Sulf2-expressing region) overlapped with the Shh expression domain, and always followed the strong expression of Patched1 (Fig. 1j), it is also likely, even in the mouse, that this strong Shh signaling subsequently induces Sulf1 gene expression and further Shh signaling input in the dorsal cells. Our work also showed that the Shh-expressing region failed to expand dorsally into the $\mathrm{p} 3$ domain, and its expression was restricted to the floor plate even at E11.5 (Fig. 3a-c) and E12.5 (fig. 3d-f) in both Sulf1 KO and Sulf2 KO mice although previous work demonstrated that the expression of Shh in the developing spinal cord was not dependent on Sulf1 activity $[12,30]$. One potential explanation for this discrepancy is that the use of thinner tissue sections instead of sections of $60-80 \mu \mathrm{m}$, which were used in the previous studies, enabled us to detect relatively small changes in gene expression. In addition to Shh expression, the expression of the Shh signaling indicator Patched 1 was also altered in Sulf1 KO and Sulf2 KO mice. At E11.5, Patched1 expression appeared weaker in the KOs than in WT mice (Fig. 3g-i), which is consistent with the Sulf1 knockdown phenotype in zebrafish [30]. At E12.5, the Patched1 expression pattern remained unchanged from E11.5 in Sulf1 KO and Sulf2 KO mice, with a strong signal accumulating in the pMN domain (Fig. 3h, $\mathrm{i}, \mathrm{k}, \mathrm{l})$. These phenotypes support the hypothesis that a mechanism similar to that operating in zebrafish is also operating in the mouse. Sulf1 and Sulf2 are well known to specifically remove glucosamine 6-O-sulfate groups from HS chains in HSPGs [26]. In addition, the loss of Sulf1 and/or Sulf2 in mice significantly increases the amount of trisulfated disaccharides in the central nervous system and other organs [32]. Importantly, HSPGs regulate Shh processing and release, and HS acts as a scaffold or activator for Shh ligands [44]. Surface plasmon resonance analysis has shown that Shh preferentially binds to highly sulfated HS [45]. Previous work in Drosophila and Xenopus showed that Sulf1 influences the Hh/Shh gradient by releasing $\mathrm{Hh} / \mathrm{Shh}$ from the cell surface $[27,28]$. Therefore, it is reasonable to consider that Sulf1 and Sulf2 reduce the interaction between Shh/HSPG by removing 6-O-sulfate groups from the HS chains to release Shh. The released Shh can subsequently diffuse dorsally to input strong Shh signaling onto the dorsal neighboring cells. This explains why strong Shh signaling input always precedes the expression of sulfatases (Sulf1 and the strong Sulf2 expression domain) from E10.5 to E12.5 (Fig. 1j). Thus, in the
Sulf1 KO and Sulf2 KO mice, inefficient cleavage of 6-Osulfate from HS results in Shh insufficiency in the dorsal region, leading to weak Shh signaling input particularly in the pMN domain at E11.5. It is well known that strong Shh activity in the pMN domain is required for the MNto-OPC fate switch and for the expansion of Nkx2.2 expressionintothepMNdomain. ThisallowsOlig2+Nkx2.2+ cells to then differentiate into OPCs [10]. Due to the failed induction of Shh expression in the p3 domain, the accumulation of Shh signaling in the pMN domain is insufficient at E11.5 in Sulf KO mice. This could cause a ventral shift in the p3 and pMN domain and delay the MN-toOPC fate change. This would result in prolonged $\mathrm{MN}$ generation, which would typically end by E12.5 (Fig. 7a$\mathrm{k}$ ), and markedly reduced OPC generation at E12.5 (Fig. 5a-c, g).

Although the dorsal expansion of Shh, Sulf1, and Sulf2 appeared to be induced by strong Shh signaling, Sulf1 and Sulf2 expression was normal in the Sulf2 and Sulf1 KO mice, respectively, at both protein and mRNA levels (Fig. 2a-h). This suggests that the Shh concentration required for sulfatase expansion is lower than that required for the MN-to-OPC fate switch. Given that Sulf1 and Sulf2 expression was unchanged in Sulf2 KO and Sulf1 $\mathrm{KO}$ mice, respectively, it raised the question as to why residual Sulf2 or Sulf1 activity was unable to compensate for the loss of Sulf1 or Sulf2 in the developing mouse spinal cord. There are 2 possible alternatives. One is that an interaction between Sulf1 and Sulf2 is required for their sulfatase activity; however, this possibility was eliminated by results from the sulfatase activity assay (Table 1). Another possibility is that for the precise MN-to-OPC fate switch, there is a threshold in total sulfatase activity in the pMN domain that is required to induce strong Shh signaling, suggesting that the amount of Shh released by Sulf1 or Sulf2 alone is insufficient for the fate switch. This hypothesis was confirmed by the analysis of Sulf DKO and DHe mice. All 4 Sulf mutant mouse strains (Sulf1 KO, Sulf2 KO, Sulf DKO, and Sulf DHe) showed a similar phenotype (online suppl. Fig. 3, 4), and the Sulf DKO did not show a more severe phenotype. This indicates that the $\mathrm{MN}$-to-OPC fate change is not linearly related to sulfatase activity. Only when total sulfatase activity reaches the threshold can the MN-to-OPC fate change occur.

Shh activity is generally thought to function in a concentration-dependent manner, although the duration of Shh signaling can also affect cellular responses. In the vertebrate central nervous system, the pattern of cellular differentiation is regulated by both the concentration and duration of Shh exposure [40, 46]. Dessaud et al. [47, 48]
372

Dev Neurosci 2017;39:361-374

DOI: $10.1159 / 000464284$
Jiang et al. 
showed that changing either the concentration or duration of Shh has an equivalent effect on intracellular signaling, and cells remain sensitive to the change in Shh signaling for an extended time, reverting to precursor identity if signaling levels fall below the threshold. Our study demonstrated that a lack of Sulf activity results in insufficient Shh signaling input to the pMN domain and delays the MN-to-OPC fate change but does not completely inhibit OPC generation. This is consistent with studies by Dessaud et al. [7]. It also supports the hypothesis that an extended duration of Shh signaling can compensate for low levels of Shh to control cell differentiation.

Our present work characterized a new function for Sulf2 as a positive regulator of the Shh-dependent MNto-OPC fate switch. Compared to Sulf1, Sulf2 was more widely distributed throughout the ventral spinal cord, where its expression can be divided into 2 parts: a strong and a weak expression domain (Fig. 1a-f). In this study, we characterized the function of this strong Sulf2 expression, which overlapped with the region of Sulf1 expression. However, we were unable to elucidate the function of Sulf2 in the weakly expressing region during embryonic spinal cord development. Its weak expression may involve fibroblast growth factor (FGF) signaling. Dynamic changes in HS 6-O sulfation correlate with modulated sensitivity to FGF signal transduction during neural development [49], and Sulf1 and/or Sulf2 null mice showed increased signaling in response to FGF-2 [50]. In addition, FGFs also act as inducers of OPCs in the dorsal spi- nal cord [51]. It is possible that the region of weak Sulf2 expression is associated with FGF-regulated signaling.

In conclusion, our study identified a new role for Sulf2 as a positive Shh signaling modulator in the regulation of the MN-to-OPC fate change in the developing ventral spinal cord. Our study also suggests that there is a threshold of sulfatase activity, which is likely reflected in the dose of Shh required to induce the MN-to-OPC fate switch.

\section{Acknowledgments}

This work was supported by research grants from the Japanese Society for the Promotion of Science (JSPS) KAKENHI (26290027 to K.I. and 25293065 to M.M.) and by Grants-in-Aid for Scientific Research on Innovative Areas (25123721 to K.I., 22123006 to M.M., and 23110002 to K.K.). We thank the Spectrography and Bioimaging Facility and the Functional Genomics Facility, NIBB Core Research Facilities, for technical support.

\section{Disclosure Statement}

The authors declare to have no competing financial interests.

\section{Author Contributions}

W.J. and Y.I. carried out the experiments, analyzed the data, and wrote the paper. H.H., K.K.-M. and M.M. carried out the experiments. K.U. and K.K. provided protocols and advised on the experiments. T.Y. wrote the paper. K.I. supervised the project and wrote the paper.

\section{References}

1 Echelard Y, Epstein DJ, St-Jacques B, Shen L, Mohler J, McMahon JA, McMahon AP: Sonic hedgehog, a member of a family of putative signaling molecules, is implicated in the regulation of CNS polarity. Cell 1993;75:14171430.

2 Roelink H, Porter JA, Chiang C, Tanabe Y, Chang DT, Beachy PA, Jessell TM: Floor plate and motor neuron induction by different concentrations of the amino-terminal cleavage product of sonic hedgehog autoproteolysis. Cell 1995;81:445-455.

3 Chamberlain CE, Jeong J, Guo C, Allen BL, McMahon AP: Notochord-derived Shh concentrates in close association with the apically positioned basal body in neural target cells and forms a dynamic gradient during neural patterning. Development 2008;135:1097-1106.
4 Goodrich LV, Johnson RL, Milenkovic L, McMahon JA, Scott MP: Conservation of the hedgehog/patched signaling pathway from flies to mice: induction of a mouse patched gene by hedgehog. Genes Dev 1996;10:301312.

5 Lee J, Platt KA, Censullo P, Ruiz i Altaba A: Gli1 is a target of sonic hedgehog that induces ventral neural tube development. Development 1997; 124:2537-2552.

6 Jessell TM: Neuronal specification in the spinal cord: inductive signals and transcriptional codes. Nat Rev Genet 2000;1:20-29.

7 Dessaud E, McMahon AP, Briscoe J: Pattern formation in the vertebrate neural tube: a sonic hedgehog morphogen-regulated transcriptional network. Development 2008; 135 : 2489-2503.
8 Lu DC, Niu T, Alaynick WA: Molecular and cellular development of spinal cord locomotor circuitry. Front Mol Neurosci 2015;8:25.

9 Miller RH: Regulation of oligodendrocyte development in the vertebrate CNS. Prog Neurobiol 2002;67:451-467.

10 Fu H, Qi Y, Tan M, Cai J, Takebayashi H, Nakafuku M, Richardson W, Qiu M: Dual origin of spinal oligodendrocyte progenitors and evidence for the cooperative role of Olig2 and $\mathrm{Nkx} 2.2$ in the control of oligodendrocyte differentiation. Development 2002;129:681693.

11 Lee SK, Lee B, Ruiz EC, Pfaff SL: Olig2 and Ngn2 function in opposition to modulate gene expression in motor neuron progenitor cells. Genes Dev 2005;19:282-294.
Sulfatase Modulation of Shh Gradient during MN-to-OPC Cell Fate Change
Dev Neurosci 2017;39:361-374 DOI: $10.1159 / 000464284$ 
12 Touahri Y, Escalas N, Benazeraf B, Cochard P, Danesin C, Soula C: Sulfatase 1 promotes the motor neuron-to-oligodendrocyte fate switch by activating Shh signaling in Olig2 progenitors of the embryonic ventral spinal cord. J Neurosci 2012;32:18018-18034.

13 Orentas DM, Hayes JE, Dyer KL, Miller RH: Sonic hedgehog signaling is required during the appearance of spinal cord oligodendrocyte precursors. Development 1999;126: 2419-2429.

14 Agius E, Soukkarieh C, Danesin C, Kan P, Takebayashi H, Soula C, Cochard P: Converse control of oligodendrocyte and astrocyte lineage development by sonic hedgehog in the chick spinal cord. Dev Biol 2004;270:308321 .

15 Park HC, Shin J, Appel B: Spatial and temporal regulation of ventral spinal cord precursor specification by hedgehog signaling. Development 2004;131:5959-5969.

16 Rowitch DH, Kriegstein AR: Developmental genetics of vertebrate glial-cell specification. Nature 2010;468:214-222.

17 Bernfield M, Gotte M, Park PW, Reizes O, Fitzgerald ML, Lincecum J, Zako M: Functions of cell surface heparin sulfate proteoglycans. Annu Rev Biochem 1999;68:729-777.

18 Selleck SB: Genetic dissection of proteoglycan function in Drosophila and C. elegans. Semin Cell Dev Biol 2001;12:127-134.

19 Song HH, Filmus J: The role of glypicans in mammalian development. Biochim Biophys Acta 2002;1573:241-246.

20 Esko JD, Selleck SB: Order out of chaos: assembly of ligand binding sites in heparan sulfate. Annu Rev Biochem 2002;71:435-471.

21 Princivalle M, de Agostini A: Developmental roles of heparin sulfate proteoglycans: a comparative review in Drosophila, mouse and human. Int J Dev Biol 2002;46:267-278.

22 Belting M: Heparan sulfate proteoglycan as a plasma membrane carrier. Trends Biochem Sci 2003;28:145-151.

23 Lin X: Functions of heparan sulfate proteoglycans in cell signaling during development. Development 2004;131:6009-6021.

24 Rabenstein DL: Heparin and heparan sulfate: structure and function. Nat Prod Rep 2002; 19:312-331.

25 Yan D, Lin X: Shaping morphogen gradients by proteoglycans. Cold Spring Harb Perspect Biol 2009;1:a002493.

26 Morimoto-Tomita M, Uchimura K, Werb Z, Hemmerich S, Rosen SD: Cloning and characterization of two extracellular heparin-degrading endosulfatases in mice and humans. J Biol Chem 2002;277:49175-49185.

27 Wojcinski A, Nakato H, Soula C, Glise B: DSulfatase-1 fine-tunes hedgehog patterning activity through a novel regulatory feedback loop. Dev Biol 2011;358:168-180.
28 Ramsbottom SA, Maguire RJ, Fellgett SW, Pownall ME: Sulf1 influences the Shh morphogen gradient during the dorsal ventral patterning of the neural tube in Xenopus tropicalis. Dev Biol 2014;391:207-218.

29 Danesin C, Agius E, Escalas N, Ai X, Emerson C, Cochard P, Soula C: Ventral neural progenitors switch toward an oligodendroglial fate in response to increased sonic hedgehog (Shh) activity: involvement of sulfatase 1 in modulating Shh signaling in the ventral spinal cord. J Neurosci 2006;26:5037-5048.

30 Al Oustah A, Danesin C, Khouri-Farah N, Farreny MA, Escalas N, Cochard P, Glise B, Soula C: Dynamics of sonic hedgehog signaling in the ventral spinal cord are controlled by intrinsic changes in source cells requiring sulfatase 1. Development 2014;141:1392-1403.

31 Ratzka A, Mundlos S, Vortkamp A: Expression patterns of sulfatase genes in the developing mouse embryo. Dev Dyn 2010;239:17791788.

32 Winterbottom EF, Pownall ME: Complementary expression of HSPG 6-O-endosulfatases and 6-O-sulfotransferases in the hindbrain of Xenopus laevis. Gene Expr Patterns 2008;9:166-172.

33 Nagamine S, Tamba M, Ishimine H, Araki K, Shiomi K, Okada T, Ohto T, Kunita S, Takahashi S, Wismans RG, van Kuppevelt TH, Masu M, Keino-Masu K: Organ-specific sulfation patterns of heparan sulfate generated by extracellular sulfatases Sulf1 and Sulf2 in mice. J Biol Chem 2012;287:9579-9590.

34 Ding L, Takebayashi H, Watanabe K, Ohtsuki T, Tanaka KF, Nabeshima Y, Chisaka O, Ikenaka K, Ono K: Short-term lineage analysis of dorsally derived Olig3 cells in the developing spinal cord. Dev Dyn 2005;234:622-632.

35 Lemjabbar-Alaoui $H$, van Zante A, Singer MS, Xue Q, Wang YQ, Tsay D, He B, Jablons DM, Rosen SD: Sulf-2, a heparan sulfate endosulfatase, promotes human lung carcinogenesis. Oncogene 2009;29:635-646.

36 Rosen SD, Lemjabbar-Alaoui H: Sulf-2: an extracellular modulator of cell signaling and a cancer target candidate. Expert Opin Ther Targets 2010;14:935-949.

37 Phillips JJ, Huillard E, Robinson AE, Ward A, Lum DH, Polley MY, Rosen SD, Rowitch DH, Werb Z: Heparan sulfate sulfatase SULF2 regulates PDGFRa signaling and growth in human and mouse malignant glioma. J Clin Invest 2012;122:911-922.

38 Kicheva A, Bollenbach T, Ribeiro A, Valle HP, Lovell-Badge R, Episkopou V, Briscoe J: Coordination of progenitor specification and growth in mouse and chick spinal cord. Science 2014;345:1254927.

39 Wetts R, Vaughn JE: Manipulation of intracellular calcium has no effect on rate of migration of rat autonomic motor neurons in organotypic slice cultures. Neuroscience 2000; 98:369-376.
40 Harfe BD, Scherz PJ, Nissim S, Tian H, McMahon AP, Tabin CJ: Evidence for an expansion-based temporal Shh gradient in specifying vertebrate digit identities. Cell 2004;118: 517-528.

41 Pringle NP, Yu WP, Guthrie S, Roelink H, Lumsden A, Peterson AC, Richardson WD: Determination of neuroepithelial cell fate: induction of the oligodendrocyte lineage by ventral midline cells and sonic hedgehog. Dev Biol 1996;177:30-42.

42 Kicheva A, Briscoe J: Developmental pattern formation in phases. Trends Cell Biol 2015; 25:579-591.

43 Dhoot GK, Gustafsson MK, Ai X, Sun W, Standiford DM, Emerson CP Jr: Regulation of Wnt signaling and embryo patterning by an extracellular sulfatase. Science 2001;293: 1663-1666

44 Ortmann C, Pickhinke U, Exner S, Ohlig S, Lawrence R, Jboor H, Dreier R, Grobe K: Sonic hedgehog processing and release are regulated by glypican heparan sulfate proteoglycans. J Cell Sci 2015;8:2374-2385.

45 Zhang F, McLellan JS, Ayala AM, Leahy DJ, Linhardt RJ: Kinetic and structural studies on interactions between heparin or heparan sulfate and proteins of the hedgehog signaling pathway. Biochemistry 2007;46:3933-3941.

46 Briscoe J, Ericson J: Specification of neuronal fates in the ventral neural tube. Curr Opin Neurobiol 2001;11:43-49.

47 Dessaud E, Yang LL, Hill K, Cox B, Ulloa F, Ribeiro A, Mynett A, Novitch BG, Briscoe J: Interpretation of the sonic hedgehog morphogen gradient by a temporal adaptation mechanism. Nature 2007;450:717-720.

48 Dessaud E, Ribes V, Balaskas N, Yang LL, Pierani A, Kicheva A, Novitch BG, Briscoe J, Sasai N: Dynamic assignment and maintenance of positional identity in the ventral neural tube by the morphogen sonic hedgehog. PLoS Biol 2010;8:e1000382.

49 Brickman YG, Ford MD, Gallagher JT, Nurcombe V, Bartlett PF, Turnbull JE: Structural modification of fibroblast growth factorbinding heparin sulphate at a determinative stage of neural development. J Biol Chem 1998;273:4350-4359.

50 Lamanna WC, Baldwin RJ, Padva M, Kalus I, Ten Dam G, van Kuppevelt TH, Gallagher JT, von Figura K, Dierks T, Merry CL: Heparan sulfate 6-O-endosulfatases: discrete in vivo activities and functional co-operativity. Biochem J 2006;400:63-73.

51 Chandran S, Kato H, Gerreli D, Compston A, Svendsen CN, Allen ND: FGF-dependent generation of oligodendrocytes by a hedgehog-independent pathway. Development 2003;130:6599-6609. 